\title{
Modern moral judgments show traces of both ancient and culturally recent sanctioning systems
}

\author{
Boyoung $\operatorname{Kim}^{\mathrm{a}}$ * \\ aDepartment of Cognitive, Linguistic, \& \\ Psychological Sciences, \\ 190 Thayer Street, Brown University, \\ Providence, RI, USA \\ boyoung_kim_1@brown.edu)
}

\author{
John Voiklis ${ }^{b}$

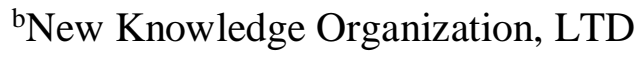 \\ 40 Exchange Place, Suite 1403, \\ New York, NY, USA \\ jvoiklis@newknowledge.org
}

Bertram F. Malle

aDepartment of Cognitive, Linguistic, \& Psychological Sciences, 190 Thayer Street, Brown University, Providence, RI, USA bfmalle@brown.edu

*Corresponding author 


\begin{abstract}
Modern human societies demand enforcement of social and moral norms using two types of sanctions that have distinct historical origins. Informal sanctions (e.g., chiding a relative) have existed since the dawn of humanity, whereas formal sanctions (e.g., punishment by the state) emerged more recently - over the last few thousand years, when laws began to separate norm violations into illegal and non-illegal violations. However, little research has investigated the psychological mechanisms underlying people's use of these two distinct systems of sanctions. We show for the first time that these different cultural histories have left detectable traces in people's moral judgments of today. When considering formal sanctions, people are experts in discriminating among illegal violations of varying severity, which is an adaptation to the culturally recent introduction of authority and law. When considering light informal sanctions (e.g., disapproval), people are experts in discriminating among non-illegal violations of varying severity, which serves the regulation of countless social norms of modern times. Most strikingly, when considering heavy informal sanctions (e.g., lashing out), people show equal discrimination expertise for both illegal and non-illegal violations, which likely reflects the moral responses of ancient group living.
\end{abstract}

Six Keywords. Morality, Formal Sanctions, Informal Sanctions, Cultural Evolution, Blame, Punishment 
Modern society regulates norm violations through two systems of sanctions: informal and formal (Horwitz, 1990). Informal sanctions refer to community members' verbal and non-verbal expressions of moral criticism directed at transgressors (Anderson, Chiricos, \& Waldo, 1977; Ellickson, 1991), such as chiding a friend for breaking a promise or frowning at a train passenger who loudly talks on the phone (Przepiorka \& Berger, 2016). By contrast, formal sanctions refer to various forms of punishment that are enforced by authorities, including legal institutions and government agencies (Anderson et al., 1977; Cushman, 2015), which impose reprimands, imprisonment, and sometimes death.

Today, both systems of sanctions serve a common purpose of regulating norm-violating behavior, but informal and formal sanctions have separate historic origins and functions. Whereas informal sanctions have regulated human society for hundreds of thousands of years, since the era of hunters and gatherers (Boehm, 1999), formal sanctions emerged much more recently. They were born in the wake of human settlement, agricultural advancement, rapid population growth, and social stratification into hierarchies (Bogucki, 1999; Price, 1995). As people accumulated private possessions, wealth, and positions of power, institutions of authority arose to protect and expand those assets through laws of inheritance, labor, trade and more (Binder, 2002; Casari, 2007; Milgrom, North, \& Weingast, 1990; Ostrom, 2000; Sterelny, 2016).

In light of these different cultural histories of formal and informal sanctions, the present research examined whether we can track distinct cognitive traces of the two sanctions in moral judgments of people today. In particular, we examined as one such trace the differential cognitive expertise people show when using formal and informal sanctions. In analogy to perceptual expertise (Gauthier, Tarr, \& Bub, 2010), which enables people to finely discriminate among certain kinds of stimuli, cognitive expertise in the moral domain would be demonstrated by people's ability to finely discriminate among norm violations of varying severity. But, according to our hypothesis, these discriminations should differ between informal and formal sanctions. Specifically, a unique feature of formal sanctions is that they emerged to regulate a subset of violations, namely illegal ones, carved out by the new institutions of authority of human settlement. People may therefore have become experts in evaluating formal sanctions for illegal violations. That is, when imposing formal sanctions, people should more finely discriminate the severity of violations within the class of illegal violations than within the class of non-illegal violations (Hypothesis Formal, $\mathrm{H}_{\mathrm{F}}$ ). By contrast, because informal sanctions emerged 
much earlier in human history to regulate any kind of norm violation, people should show equal expertise between illegal and non-illegal violations. That is, when imposing informal sanctions, they should discriminate equally well the severity of all violations, whether illegal or non-illegal (Hypothesis Informal, $\mathrm{H}_{1}$ ).

\section{Methodological Approach}

Whereas early moral judgment research considered punishment judgments (representing formal sanctions) and blame judgments (representing informal sanctions) as distinct (e.g., Fincham \& Shultz, 1981; Shaver, 1985; Shultz \& Darley, 1991), more recent work has often treated them as theoretically interchangeable (Ames \& Fiske, 2013; Cushman, 2008) or averaged them in measurement (Goldberg, Lerner, \& Tetlock, 1999; Rothschild, Landau, Sullivan, \& Keefer, 2012). To test our hypotheses we needed to measure the two types of sanctions separately — and we did so as a between-subjects manipulation in Study 1 and as within-subject response options in Studies 2 and 3.

Even though illegal violations are only a subset of all violations, much of moral judgment research has focused on illegal and severe violations, such as murdering someone (Knobe, 2003; Young, Cushman, Hauser, \& Saxe, 2007) or making a life-and-death decision about multiple strangers (Christensen, Flexas, Calabrese, Gut, \& Gomila, 2014; Greene, Sommerville, Nystrom, Darley, \& Cohen, 2001). These kinds of violations are important, but they cover only one quadrant of the space of violations. Many norm violations with which people grapple in their daily lives are mild and not illegal (Black, 1995), including such violations as talking during a movie, telling an offensive joke, or lying to get out of a work assignment (Hofmann, Brandt, Wisneski, Rockenbach, \& Skitka, 2018; Hofmann, Wisneski, Brandt, \& Skitka, 2014; Stohr, 2011). To test our hypotheses we needed to examine both illegal and non-illegal violations, across the full range of severity. Only then can we assess people's differential expertise in applying formal and informal sanctions to different classes of norm violations. 
We now restate our hypotheses and illustrate the predicted results in the way in which we will formally analyze them.

\section{Hypotheses}

We operationalize cognitive expertise as discriminative ability, as the degree of linear relationship (slope) between the severity of norm violations and the strength of endorsed sanctions. As both panels of Figure 1 show, we expect that with increasing severity of norm violations, support for sanctions steeply increases. But for formal sanctions a specific pattern should hold (left panel of Figure 1):

$\mathrm{H}_{\mathrm{F}}$ : When imposing formal sanctions, people discriminate the severity of violations more finely within the class of illegal violations than within the class of non-illegal violations. That is, formal sanctions should show a steeper slope of discrimination for illegal than for non-illegal violations.

By contrast, informal sanctions should show this pattern (right panel of Figure 1):

$\mathrm{H}_{\mathrm{I}}$ : When imposing informal sanctions, people should discriminate the severity of all violations equally well, whether illegal or non-illegal.

In three studies we tested these hypotheses by assessing people's support for formal sanctions as ascriptions of deserved punishment (Study 1) and as judged appropriateness of contacting the police (Studies 2 and 3); we assessed support for informal sanctions as ascriptions of deserved blame (Study 1) and the judged appropriateness of expressing moral criticism (Studies 2 and 3). 


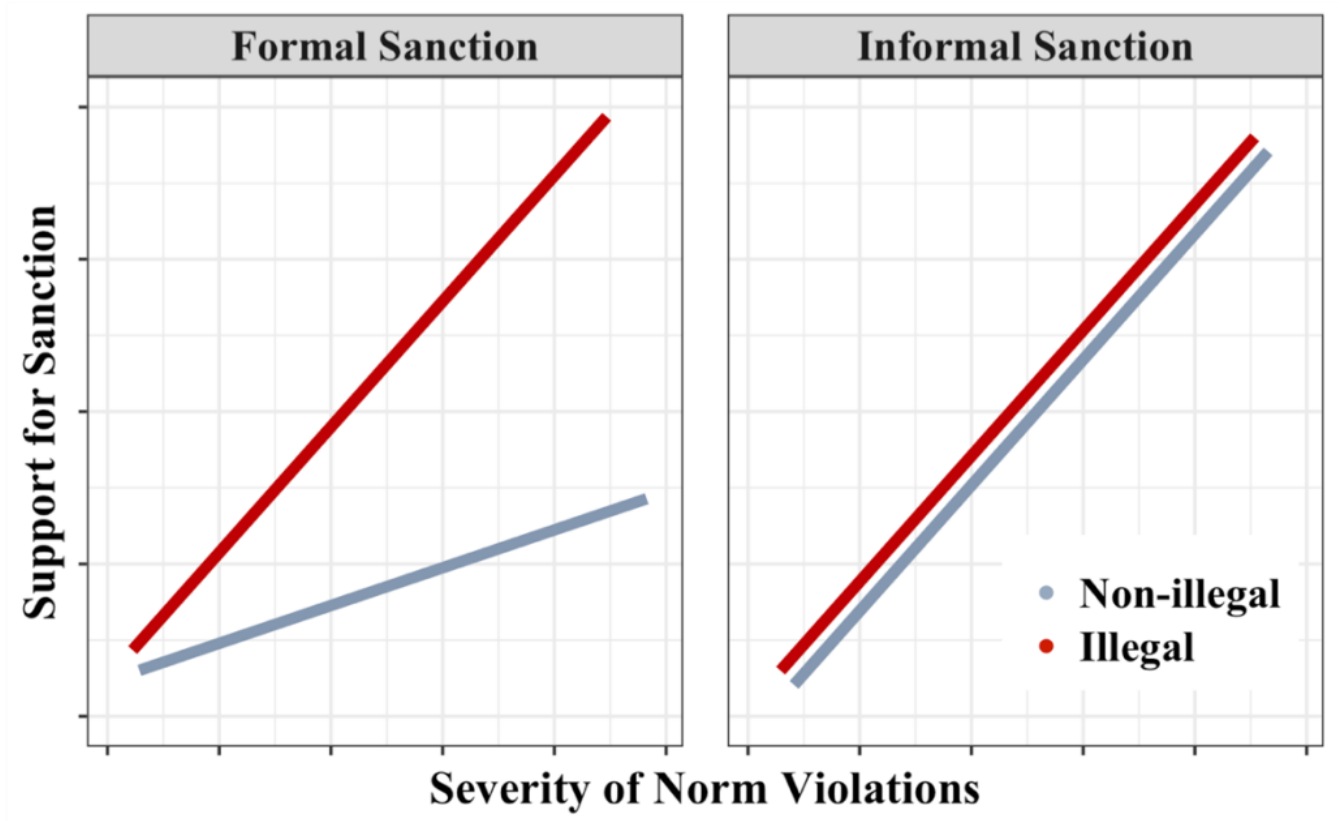

Figure 1. Visual depiction of the predicted results. For both formal and informal sanctions, as the severity of norm violations increases, support for sanctions linearly increases. However, for formal sanctions this linear increase should be steeper for illegal violations than for non-illegal violations, whereas for informal sanctions it is the same.

\section{Study 1}

\section{Methods}

The current research was approved by the Human Research Protection Program (HRPP) at Brown University and was conducted in accordance with their guidelines. All studies were conducted online via Amazon Mechanical Turk (MTurk), and participants provided informed consent before their participation.

Participants. In the relevant literature, no previous studies were available to guide effect size estimates in mixed effects designs with an interaction term. In one study, participants made punishment judgments of two different types of norm violations (Buckholtz et al., 2008), somewhat analogous to our predicted difference in punishment differentiation within illegal and non-illegal violations. The observed effect size in the previous study was very large $(d>0.8)$ in a within-subject design using 20 violation items per condition and 16 participants. We assumed a more conservative effect size and therefore aimed to recruit approximately twice as large a 
sample size per condition (punishment, blame), and we used 24 violation items on which to base the judgment discrimination estimates. Thus, we randomly assigned the predetermined number of 60 participants to either the blame task or the punishment task. (Additionally, we asked a separate group of participants to make moral wrongness judgments, which tested independent hypotheses about the difference between blame and wrongness. See the Supplemental Material.)

Thirty-one participants (20 male, 11 female, $M$ age $=32.45, S D$ age $=10.40)$ completed the punishment task. Twenty-nine participants completed the blame task, but one of them selected the same rating response for all 24 norm-violating behaviors. As the severity of the stimuli ranged from mildly bad to extremely bad, we judged that this was a clear indicator of the participant's lack of engagement in the task. After removing this participant's responses, we analyzed the responses collected from the remaining 28 participants (19 male, 9 female, $M$ age $=$ 32.21, SD age $=12.03$ ).

Stimuli. We initially created 65 norm violation stimuli and conducted pretests that measured (in separate groups of participants) the severity and the perceived illegality of norm violations. Based on these pretest results, we selected 12 illegal and 12 non-illegal norm violation stimuli whose violation severity ranged from mild to severe. (Further information is available in the Supplemental Material.)

Procedure. A vast number of moral responses in everyday life are made from thirdperson perspectives, where the evaluator learns about a violation (e.g., in the news or from acquaintances) and recommends or endorses informal or formal sanctions (Black, 1995; Hofmann et al., 2018, 2014). Participants therefore read about 24 norm-violating behaviors and were randomly assigned to one of two sanction conditions. In the informal-sanction condition, they rated how much blame they thought the transgressor of each violation deserved, using a scale of 0 (No blame at all) to 8 (Maximum blame possible). Blame is a widely accepted measurement of everyday, informal judgment (Alicke, Buckingham, Zell, \& Davis, 2008; Guglielmo \& Malle, 2017; Malle, Guglielmo, \& Monroe, 2014). Participants in the formalsanction condition made judgments of punishment on the same norm-violating behaviors and indicated how much punishment they thought the transgressor deserved on a scale of 0 (No punishment at all) to 8 (Maximum punishment possible). Supporting the operationalization of informal sanctions as punishment judgments, previous research showed that, when making such punishment judgments, people represent lower punishment ratings as light legal sanctions, such 
as small fines, and higher punishment ratings as heavy legal sanctions, such as life imprisonment (Buckholtz et al., 2008; Lieberman \& Linke, 2007). After the moral judgment task, participants completed a few demographic questions.

Data Analyses. For all statistical analyses and figures reported here, we used the R packages lme4 (Bates, Mächler, Bolker, \& Walker, 2015), lmerTest (Kuznetsova, Brockhoff, \& Christensen, 2017), and ggplot2 (Wickham, 2016) in the R (version 3.3.3, Team, 2017).

To statistically assess the effects of violation severity and illegality on people's assignment of blame and punishment, we separately analyzed people's punishment and blame judgments by fitting linear mixed effects models using maximum likelihood parameter estimations. We included pretested violation severity (an 8-point interval scale) and pretested illegality (a dichotomous factor of non-illegal [0] vs. illegal [1]) as fixed effects and participant variability as a random effect.

\section{Results}

People endorsed heavier punishment as the severity of violations increased, $\beta$ (severity) $=0.32, t$ $=7.72, p<.001,95 \%$ confidence interval $(95 \% \mathrm{CI})$ for $\beta=[0.24,0.40]$. More importantly, in support of $\mathrm{H}_{\mathrm{F}}$, people showed more expertise in applying punishment to illegal than non-illegal violations. The steeper slope of illegal than non-illegal violations in Figure 2 demonstrates that, when endorsing formal sanctions, people more finely discriminated among illegal than nonillegal violations, $\beta$ (severity $\times$ illegality $)=0.49, t=5.15, p<.001,95 \% \mathrm{CI}$ for $\beta=[0.30,0.68]$.

People also judged the transgressor as deserving more blame as the severity of violations increased, $\beta=0.41, t=7.82, p<.001,95 \% \mathrm{CI}$ for $\beta=[0.31,0.52]$. However, consistent with $\mathrm{H}_{\mathrm{l}}$, a non-significant interaction effect between severity and illegality verified that the slopes for illegal and non-illegal violations did not differ for blame $(p=.70)$. This indicates that, in using informal sanctions, people discriminate equally well among illegal violations of varying severity as among non-illegal ones. 

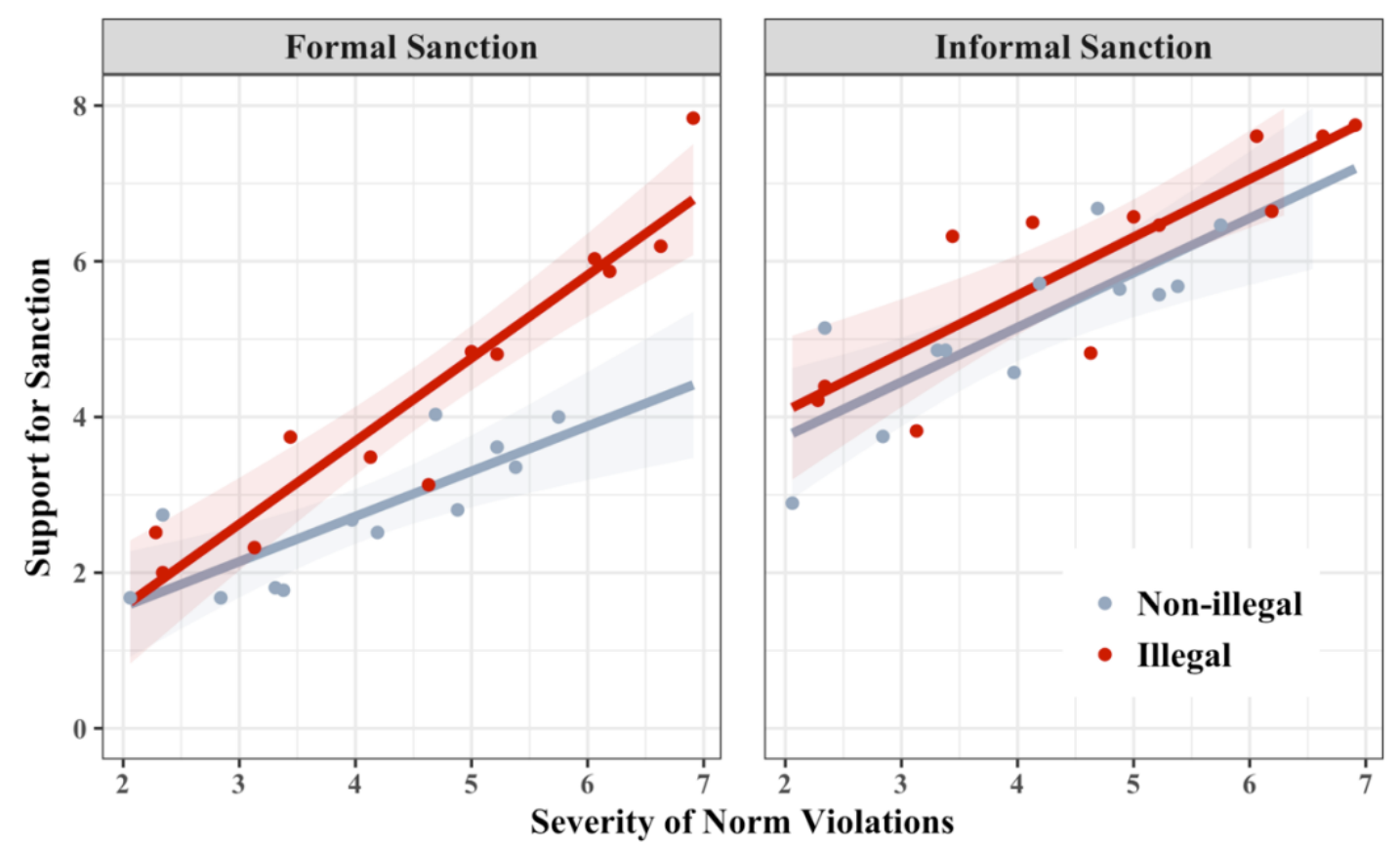

Figure 2. Support for formal sanctions (punishment, left panel) and informal sanctions (blame, right panel) as a function of severity of norm violation ( $\mathrm{x}$ axis) and type of violation (red line for illegal, grey line for non-illegal) in Study 1. Each dot represents the sample mean for one particular violation and shaded areas represent $95 \%$ confidence intervals.

\section{Discussion}

The marked difference between the two types of sanctions can be considered a cognitive trace of their distinct cultural histories. Informal sanctions are older and evolved to regulate all norm violations whereas formal sanctions emerged more recently and provide people with more focused expertise in regulating illegal violations.

Yet, there remains an alternative explanation for why, in supporting the informal sanction of blame, people were insensitive to the illegality of norm violations. Punishment recommendations directly imply a norm-enforcing action (Anderson et al., 1977; Buckholtz et al., 2008) while blame can come both as a private thought and as a public norm-enforcing action (Malle et al., 2014). Thus, it is possible that people in the blame condition were making private judgments rather than actually recommending sanctions (as the people in the punishment condition were), and in such private judgments illegality may be disregarded. In Study 2, we therefore developed a new task that ensured people would interpret blame as a social act of 
sanctioning. In this task, participants evaluated three possible social acts of sanctioning: contact the police, representing the endorsement of formal sanctions; express his/her disapproval, representing the endorsement of informal sanctions, and say nothing at all, akin to the zero points of blame and punishment in Study 1. We designated the relationship between a transgressor and a norm enforcer as friends because people are likely to impose sanctions on friends but not on strangers (Moisuc \& Brauer, 2018). However, it would be ethically questionable to ask participants to imagine that their close friends were engaged in severely bad and illegal violations, such as committing a homicide or an involuntary manslaughter. Thus, we asked participants to read about someone's norm-violating behavior and express their endorsement of the specific sanction that the transgressor's friend chose to impose.

\section{Study 2}

\section{Methods}

Participants. In this study, the dependent variables were dichotomous, so we increased the target number of participants to 100. Due to fluctuations in sampling, one hundred and eleven participants (65 male, 46 female, $M$ age $=34.80$, $S D$ age $=9.44$ ) took part in the study.

Stimuli. To improve the variety of norm-violation stimuli over the ones in Study 1, we added 12 illegal and 12 non-illegal norm violations that had not been included in Study 1, still aiming for maximally similar ranges of severity and balanced intentionality. Instead of presenting all 48 norm violation stimuli to each participant, we created 16 subsets of 12 illegal and 12 non-illegal stimuli, thus increasing stimulus generalizability without doubling the duration of the study.

Procedure. For Study 2, we designed a novel task to closely replicate people's everyday acts of moral criticism. On each of 24 trials, participants read about a norm violation and were instructed as follows: "When a friend heard about what [the transgressor's name] did, he/she had several options to respond to [the transgressor's name]'s behavior." We then provided participants with the friend's possible responses that capture sanctions as acts, rather than thoughts. One of the possible responses was say nothing at all, which is akin to no blame at all or no punishment at all in Study 1. A second possible response was contact the police, representing the endorsement of formal sanctions (Black, 1971; Thomas \& Bishop, 1984). A 
third possible response was express his/her disapproval to [the transgressor's name], representing the endorsement of informal sanctions. After reading each norm violation, people dragged and dropped the friend's three possible responses into boxes labeled Appropriate, Not appropriate, and I can't tell.

Data Analyses. We conducted mixed-effects logistic regression analyses with violation severity (an 8-point interval scale) and illegality (a dichotomous factor of non-illegal [0] vs. illegal [1]) as fixed effects and participant variability as a random effect for each response option. Here we report results for the two hypothesis-relevant options (express his/her disapproval and contact the police) and results of say nothing at all can be found in the Supplemental Material.

Only $5.61 \%$ of the responses fell into the category of I can't tell, thus people were easily able to decide whether sanction options were either appropriate or not appropriate. The I can't tell responses were excluded from data analyses.

\section{Results}

As in Study 1, with increasing severity of norm violations, people were overall more likely to support formal sanctions (contact the police), mixed-effects logistic regression odds ratio $(\mathrm{OR})=$ $1.43, z=3.04, p=.002,95 \% \mathrm{CI}$ for $\mathrm{OR}=[1.14,1.81]$. More importantly, as shown in Figure 3, they discriminated among violations of different severity only within illegal violations, not within non-illegal ones, OR (severity $\times$ illegality) $=2.63, z=7.06, p<.001,95 \% \mathrm{CI}$ for OR $=$ $[2.01,3.45]$. Therefore, we again found evidence supporting $H_{F}$. This pattern also suggests that people do not blindly demand formal sanctions whenever a violation is illegal; rather, they closely take into consideration how severe the illegal norm violation is and only gradually increase their support for formal sanctions.

The likelihood of endorsing informal sanctions (express one's disapproval) also increased with greater severity of norm violations overall, $\mathrm{OR}=2.32, z=9.67, p<.001,95 \% \mathrm{CI}$ for $\mathrm{OR}=[1.96,2.75]$. At the same time, we found that people responded differentially to illegal and non-illegal violations (see Figure 3), OR (severity $\times$ illegality) $=0.35, z=-9.10, p<.001$, $95 \% \mathrm{CI}$ for $\mathrm{OR}=[0.28,0.44]$. Specifically, in endorsing informal sanctions, people discriminated finely among non-illegal violations but not among illegal violations. Though the 
effect size of this interaction term for informal sanctions was relatively small $(\mathrm{OR}=0.35)$, the result does contradict $H_{I}$ 's prediction of no interaction.

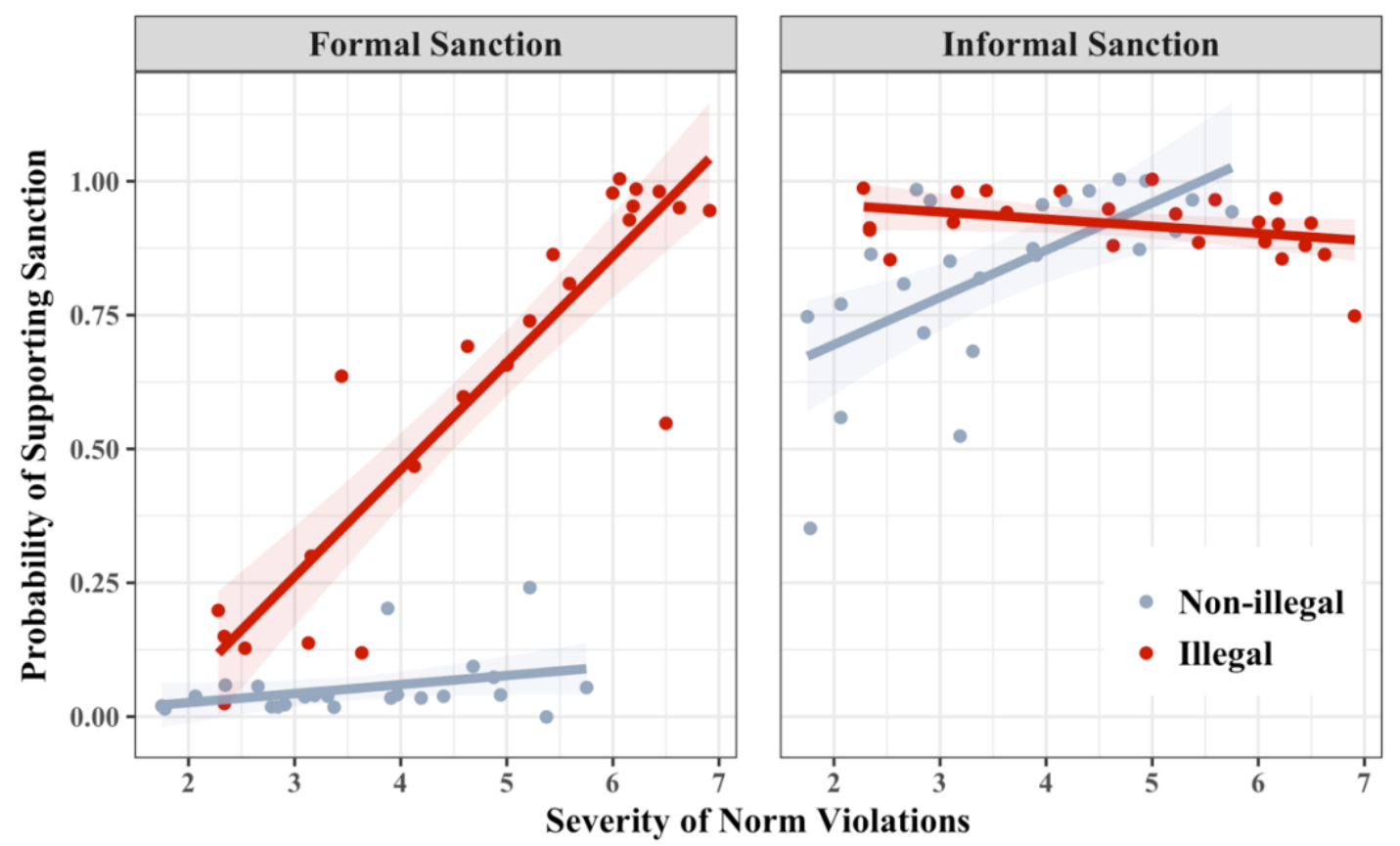

Figure 3. Probability of endorsing formal sanctions (contact the police, left panel) and informal sanctions (express disapproval, right panel) as a function of norm violation severity ( $\mathrm{x}$ axis) and type of violation (red line for illegal, grey line for non-illegal) in Study 2. Each dot represents the sample mean for one particular violation and shaded areas represent $95 \%$ confidence intervals.

\section{Discussion}

Study 2's results suggest a revised hypothesis $H_{I}$ about the cognitive trace of informal sanctions in moral evaluations of today. After the division between informal and formal sanctions a few thousand years ago, while formal sanctions became specialized in dealing with illegal violations, informal sanctions may have begun to specialize in regulating everyday, non-illegal violations.

However, participants in Study 2 readily recommended informal sanctions already for the mildest of violations (at least $75 \%$ endorsement probability for 43 out of 48 violations). This pervasive use of informal sanctions compressed judgments especially for illegal violations (see Figure 3), so people's insensitivity to these violations (contradicting $H_{I}$ ) may have been a ceiling 
effect. This effect likely emerged because the only informal sanction people were able to consider was the relatively weak express one's disapproval. In real life, when using informal sanctions to handle norm violations of varying severity, people can adjust the strength of their sanctions. Thus, if participants had a range of options (from light to heavy sanctions) in the experimental context, they may exhibit fine discrimination among all norm violations (as $\mathrm{H}_{\mathrm{I}}$ predicts) - just as they did when they had a range of degrees of blame in Study 1. In Study 3, participants were therefore invited to choose from 6 different strengths of informal sanctions.

\section{Study 3}

\section{Methods}

Participants. As in Study 2, we aimed for approximately 100 participants, and one hundred and one participants (67 male, 34 female, $M$ age $=32.98, S D$ age $=10.11$ ) completed the study.

Procedure. Study 3's norm violation stimuli and task were identical to those in Study 2. But Study 3 included one modification to the measurement of informal sanctions that allowed participants to endorse such sanctions of varying strength. Participants were able to declare the appropriateness of a list of six possible acts of moral criticism a friend could perform (criticize, chide, scold, chew out, let X have it, lash out at). For example, the option of chide was phrased as, "chide [the transgressor's name]" and the option of let X have it was phrased as "let [the transgressor's name] have it." The six verb phrases were intended to represent an ordinal scale of intensity of moral criticism as it naturally occurs when people express their criticism directly to the transgressor (Voiklis, Cusimano, \& Malle, 2014, For more information, see the Supplemental Material). In addition to this range of informal sanctions, participants considered, as before, the options of initiating formal sanctions (contact the police) and no sanction (say nothing at all).

Data Analyses. As in Study 2, we separately fitted mixed-effects logistic regression models for formal and informal sanctions. For informal sanctions, we added an additional fixed effect, namely the sanction strength of each informal sanction option (i.e., chide, criticize, scold, let $X$ have it, chew out, lash out at). The averaged (and centered) ratings of the perceived strength of each criticism option were used to represent the specific values of the sanction 
strength predictor. The small number of I can't tell responses (3.32\% of total) were excluded from data analyses.

\section{Results}

People were increasingly likely to endorse a formal sanction (contact the police) as the severity of norm violations increased, $\mathrm{OR}=1.64, z=2.85, p=.004,95 \% \mathrm{CI}$ for $\mathrm{OR}=[1.17,2.30]$. Also, as Figure 4 shows, in endorsing the formal sanction, people finely discriminated among illegal violations but not among non-illegal ones, interaction (severity $\times$ illegality): $\mathrm{OR}=2.31, z=4.45$, $p<.001,95 \% \mathrm{CI}$ for $\mathrm{OR}=[1.60,3.34]$. These patterns once more support hypothesis $\mathrm{H}_{\mathrm{F}}$.

We also found that people were overall more likely to endorse informal sanctions as the severity of norm violations increased, $\mathrm{OR}=2.20, z=29.13, p<.001,95 \% \mathrm{CI}$ for $\mathrm{OR}=[2.09$, 2.32]. Moreover, consistent with Study 2 and thus supporting the revised hypothesis $H_{l}$, people discriminated more finely among degrees of violation severity for non-illegal than illegal violations, $\mathrm{OR}($ severity $\times$ illegality $)=0.65, z=-13.15, p<.001,95 \% \mathrm{CI}$ for $\mathrm{OR}=[0.61,0.69]$ (See Figure 4).
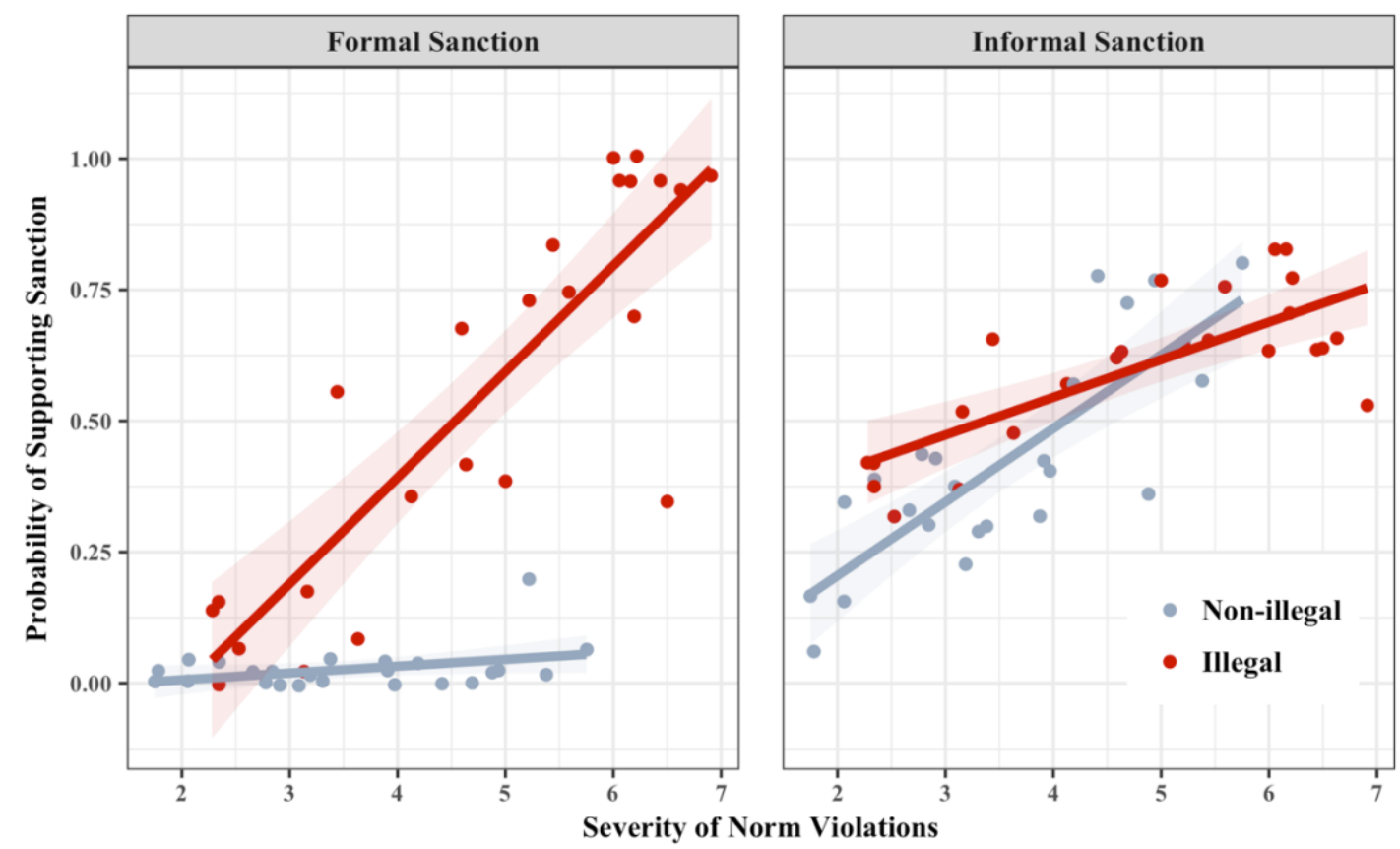

Figure 4. Probability of endorsing formal sanctions (contact the police, left panel) and informal sanctions (express disapproval, averaged across six levels of sanction strength, right panel) as a 
function of norm violation severity ( $\mathrm{x}$ axis) and type of violation (red line for illegal, grey line for non-illegal) in Study 3. Each dot represents the sample mean for one particular violation and shaded areas represent $95 \%$ confidence intervals.

However, when we included sanction strength as an additional predictor into the analysis of informal sanctions, we found that discrimination systematically varied across sanction strength (i.e., from chide through scold to lash out at), OR (severity $\times$ illegality $\times$ sanction strength) $=1.16, z=4.42, p<.001,95 \% \mathrm{CI}$ for $\mathrm{OR}=[1.09,1.24]$. Figure 5 shows each sanction level plotted as a separate function predicting people's support for sanctions from violation severity by illegality. There was a striking division of informal sanctions into two levels: light (i.e., chide, criticize, scold) and heavy (i.e., let X have it, chew out, lash out at).

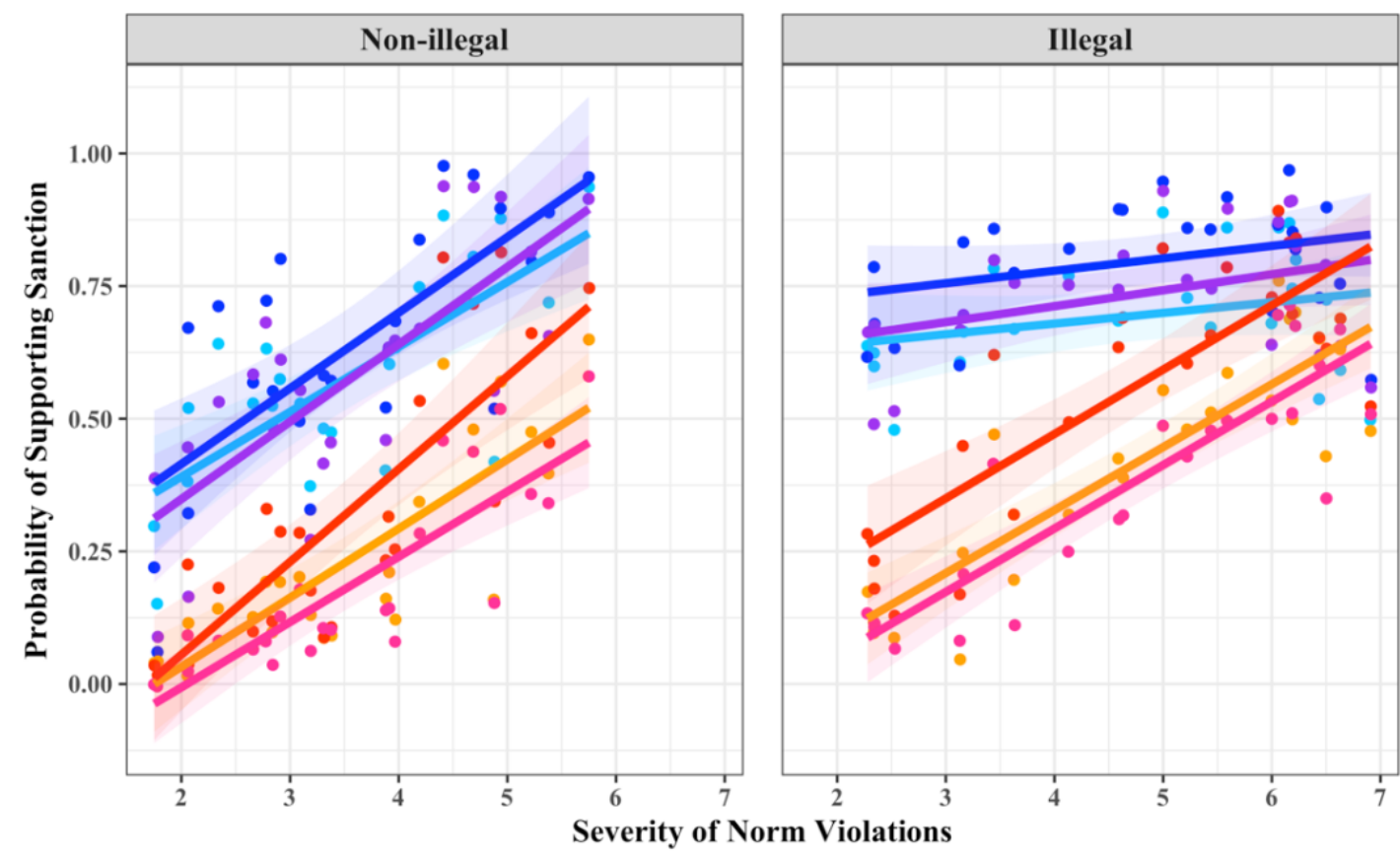

Informal Sanctions

- Chide

- Criticize

- Scold

- Let X have it

- Chew out

- Lash out at

Figure 5. Probability of endorsing informal sanctions as a function of violation severity (x axis), type of violation (non-illegal on the left, illegal on the right), and sanction strength (from chide to lash out at) in Study 3. Each dot represents the sample mean for one particular violation and shaded areas represent $95 \%$ confidence intervals. 
When endorsing heavy informal sanctions people finely discriminated among both illegal and non-illegal violations, but when endorsing light informal sanctions they discriminated more finely among non-illegal than illegal violations. These patterns resolve the divergence of Studies 1 and 2 and thus reconcile the two variants of hypothesis $H_{I}$. On the one hand, people's pattern of heavy informal sanctions looks like blame in Study 1, showing equally fine discrimination among non-illegal and illegal violations, $\mathrm{OR}$ (severity) $=2.43, z=6.52, p<.001,95 \% \mathrm{CI}$ for OR $=[1.86,3.17]$, with no significant severity $\times$ illegality interaction, $p=.14$. On the other hand, people's pattern of light informal sanctions looks like expressions of disapproval in Study 2, showing not only overall discrimination among degrees of violation severity, $\mathrm{OR}=2.32, z=$ $12.90, p<.001,95 \% \mathrm{CI}$ for $\mathrm{OR}=[2.04,2.63]$, but also more discriminative sensitivity to nonillegal than illegal violations, $\mathrm{OR}($ severity $\times$ illegality $)=0.52, z=-8.02, p<.001,95 \% \mathrm{CI}$ for $\mathrm{OR}=[0.45,0.61]$

\section{General Discussion}

Our inquiry into the cognitive traces of formal and informal sanctions' cultural histories started from two hypotheses: When people use formal sanctions they discriminate more finely among illegal than non-illegal violations, and when they use informal sanctions they discriminate equally well among illegal and non-illegal violations. Study 1 supported both of these hypotheses. Study 2 supported the hypothesis on formal sanctions but called for an amendment to the hypothesis on informal sanctions, pointing to a possible specialization of informal sanctions for non-illegal behaviors. A distinction between light and heavy informal sanctions in Study 3 reconciled the original and the amended hypotheses. Taken together, the evidence suggests a three-way division of labor between formal and informal sanctions in modern life (Figure 6). Formal sanctions are a tool specialized for coping with illegal violations; light informal sanctions are a tool specialized for coping with non-illegal violations; and heavy informal sanctions are a tool equally applicable to both illegal and non-illegal violations. 


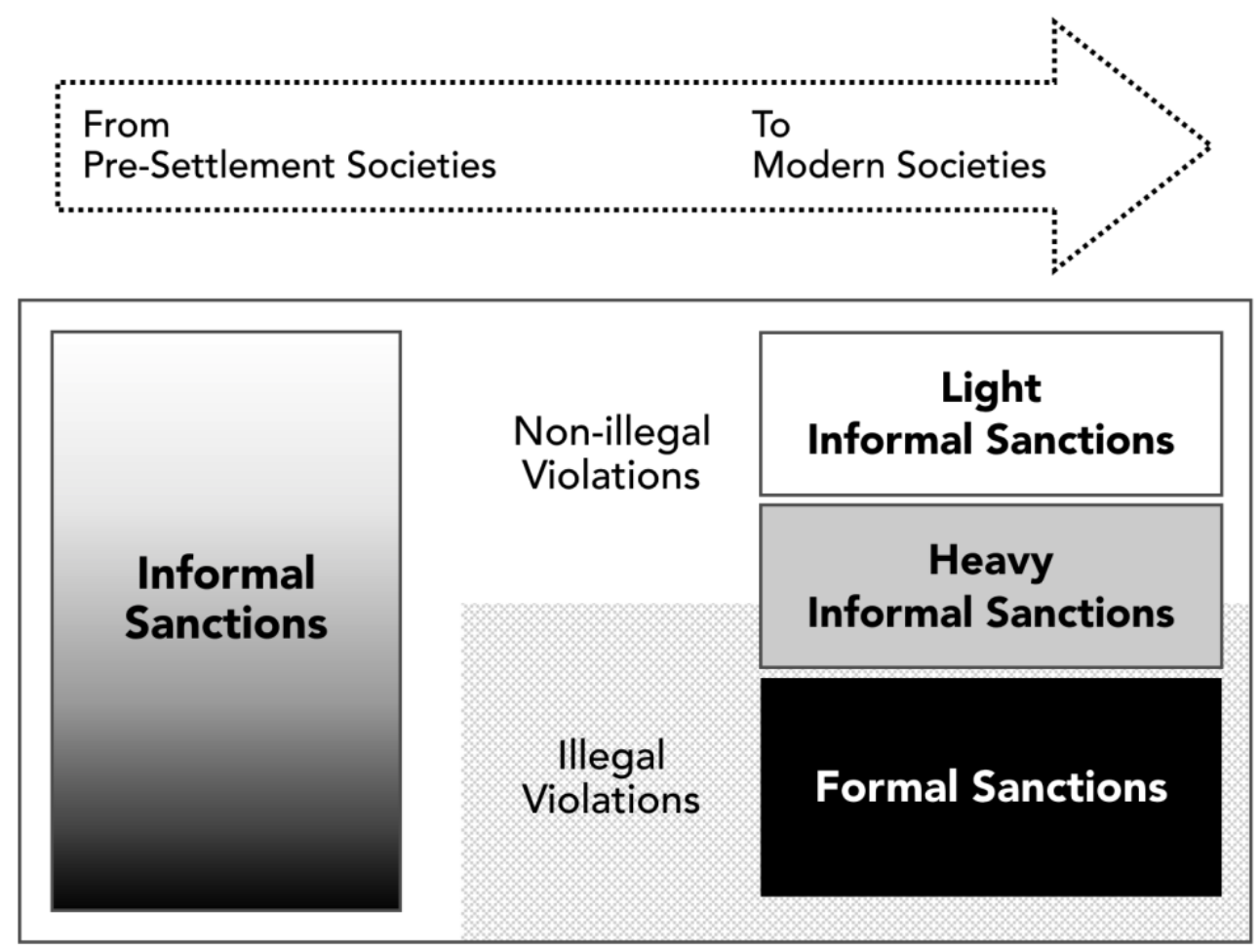

Figure 6. A schematic representation of the cultural evolution of sanctions from pre-settlement societies, when informal sanctions regulated all violations, to modern societies, when both formal and informal sanctions regulated illegal and non-illegal violations. Formal sanctions are specialized to regulate illegal violations, light informal sanctions are specialized to regulate nonillegal violations, and heavy informal sanctions are equally sensitive to both classes of violations.

Considerations of cultural history can clarify how this differentiation into three tools of sanctioning occurred. Informal sanctions were the only tool of social regulation until about 10,000 years ago, when homo sapiens for the first time settled down. Formal sanctions emerged during the radical change of social life resulting from these settlements. Communities adopted agriculture, exploded in population, and became stratified into layers of social hierarchy (Binder, 2002; Ostrom, 2000; Price, 1995). Ownership of land, livestock, and new food production required protection, and territorial expansions provoked broader and more frequent intergroup conflict that demanded military defenses. These needs for protection and defense gave rise to a political elite (Sterelny, 2016) that eventually declared formal rules and laws (e.g., King UrNammu's code; King Hammurabi's code, Harper, 1999) and had the position and means to 
execute formal sanctions (Fukuyama, 2011; Service, 1975). Our data show cognitive traces of this historically recent tool of sanctions: when people in our study endorsed formal sanctions they exhibited fine discrimination among illegal violations of varying severity.

However, our data suggest that modern life brought about another change, which differentiated the ancient tool of informal sanctions into two variants: light and heavy informal sanctions. During the growth of agriculture and urbanization, an ever more rapidly increasing number of artifacts, cultural spaces, and social roles spurred the development of numerous context-varying social norms of mild to moderate strength that govern people's daily interactions (Falk, Fehr, \& Fischbacher, 2005; Horwitz, 1990; Stohr, 2011). To effectively enforce such norms while allowing interactants to save face, maintain their relationships, and minimize retaliation, light informal sanctions emerged as a regulatory system specialized in dealing with non-illegal, everyday violations. A dismissive remark, a disapproving head shake, or a scornful frown are not intense acts of sanctioning. Even so, because of people's need to belong (Baumeister \& Leary, 1995) and their resulting sensitivity to others' acceptance and approval (Hareli, Moran-Amir, David, \& Hess, 2013), such light informal sanctions are powerful in controlling many violations in modern life.

Meanwhile, when considering heavy informal sanctions — such as lashing out, retaliating, or ostracizing — people in our study discriminated finely among all violations, illegal and nonillegal. As a result, these heavy informal sanctions may serve a unique role in bridging the illegal and non-illegal domains in modern society. When severe illegal violations cannot be delegated to authorities, or authorities have refused to deliver formal sanctions, heavy informal sanctions are the only tool that empowers people to immediately deal with these violations. For example, people in the U.S. have broken into mass protests against acquitted police officers who shot unarmed individuals or against immigrant children being separated from their parents. Also, over time, heavy informal sanctions can catalyze the creation of new laws when previously non-illegal violations are strongly condemned by the public. Consider the civil disobedience against racial injustice or the public outcry over sexual harassment in the workplace leading to the establishment of new laws. Thus, heavy informal sanctions may enable formal sanctioning systems to keep up with major cultural changes.

Some limitations of the present results are apparent. First, even though our results on formal sanctions are consistent across three studies, the distinction between light and heavy 
informal sanctions was documented across only two studies and will require additional corroboration and refinement. In particular, the distinction would be validated if it were associated with differential neural patterns, just as blame and punishment appear to have differential neural signatures (Buckholtz et al., 2008). Second, we assessed support for formal sanctions as judgments of deserved punishment and endorsements of calling the police. Additional measures would be instructive, such as recommended official fines or prison sentences (Robinson \& Darley, 1995). Likewise, informal sanctions could be measured as acts of telling others about a violation or personally retreating from the violator. Third, our experimental approach does not assess live violations or direct second-person sanctions. A live experiment involving severe violations would be unethical, but a milder version (e.g., in a game or virtual reality context) could be valuable to capture subsets of the hypothesized relationships. We believe that non-experimental methods, such as experience sampling and text analysis methods, might be a promising additional route for testing our hypotheses.

\section{Conclusion}

The interdisciplinary study of morality has provided many insights, such as into the socialcognitive, emotional, and neural processes that underlie moral judgment and into the vast array of norms and values that constitute morality. The present findings add the insight that people's formal and informal sanctioning responses show a cognitive trace of the cultural evolution of morality. The historically recent emergence of laws and formal sanctions is reflected in people's greater expertise in discriminating violations of varying severity within the illegal domain. Even more recently emerged the need to effectively regulate the myriad of mild to moderate violations of everyday social life. Light informal sanctions took on this task, and people now show greater expertise in discriminating violations within the non-illegal domain than within the illegal domain. Heavy informal sanctions, finally, bridge the gap between the legal and everyday social world. These sanctions are perhaps traces of the oldest of human moral responses, equally sensitive to all violations. 


\section{Data and Code Availability}

Data and Analyses code are available at

https://osf.io/k9g54/?view_only=f4046bd1000c49ae8458daf2e63bc108

\section{Author Contributions}

B.K., J.V., and B.F.M. developed the study concept and the study design. B.K. performed testing and data collection. B.K. and B.F.M. performed the data analysis and interpretation. B.K., J.V., and B.F.M. wrote the manuscript. All authors approved the final version of the manuscript for submission.

\section{Declaration of Conflicting Interests}

The authors declare no competing interests.

Acknowledgements This research was supported by the Office of Naval Research (ONR), N00014-13-1-0269 and N00014-16-1-2278. 


\section{References}

Alicke, M. D., Buckingham, J., Zell, E., \& Davis, T. (2008). Culpable control and counterfactual reasoning in the psychology of blame. Personality and Social Psychology Bulletin, 34, 1371-1381. https://doi.org/10.1177/0146167208321594

Ames, D. L., \& Fiske, S. T. (2013). Intentional harms are worse, even when they're not. Psychological Science, 24(9), 1755-1762. https://doi.org/10.1177/0956797613480507

Anderson, L. S., Chiricos, T. G., \& Waldo, G. P. (1977). Formal and informal sanctions: A comparison of deterrent effects. Social Problems, 25(1), 103-114. https://doi.org/10.2307/800471

Bates, D., Mächler, M., Bolker, B., \& Walker, S. (2015). Fitting linear mixed-effects models using lme4. 67(1), 1-48. Retrieved from https://arxiv.org/abs/1406.5823

Baumeister, R. F., \& Leary, M. R. (1995). The need to belong: Desire for interpersonal attachments as a fundamental human motivation. Psychological Bulletin, 117(3), 497529. https://doi.org/10.1037/0033-2909.117.3.497

Binder, G. (2002). Punishment theory: Moral or political? Buffalo Criminal Law Review, 5(2), 321-372. Retrieved from http://www.jstor.org/stable/10.1525/nclr.2002.5.2.321

Black, D. (1995). The social structure of right and wrong. Chapel Hill, NC: University of North Carolina Press.

Black, D. J. (1971). The social organization of arrest. Stanford Law Review, 23(6), 1087-1111. https://doi.org/10.2307/1227728

Boehm, C. (1999). Hierarchy in the forest: The evolution of egalitarian behavior. Cambridge, MA: Harvard University Press.

Bogucki, P. (1999). The origins of human society. Wiley. 
Buckholtz, J. W., Asplund, C. L., Dux, P. E., Zald, D. H., Gore, J. C., Jones, O. D., \& Marois, R. (2008). The neural correlates of third-party punishment. Neuron, 60(5), 930-940. https://doi.org/10.1016/j.neuron.2008.10.016

Casari, M. (2007). Emergence of endogenous legal institutions: Property rights and community governance in the Italian alps. The Journal of Economic History, 67(1), 191-226. https://doi.org/10.1017/S0022050707000071

Christensen, J. F., Flexas, A., Calabrese, M., Gut, N. K., \& Gomila, A. (2014). Moral judgment reloaded: a moral dilemma validation study. Frontiers in Psychology, 5. https://doi.org/10.3389/fpsyg.2014.00607

Cushman, F. (2008). Crime and punishment: Distinguishing the roles of causal and intentional analyses in moral judgment. Cognition, 108(2), 353-380. https://doi.org/10.1016/j.cognition.2008.03.006

Cushman, F. (2015). Punishment in humans: From intuitions to institutions. Philosophy Compass, 10(2), 117-133. https://doi.org/10.1111/phc3.12192

Ellickson, R. C. (1991). Order without law: How neighbors settle disputes. Retrieved from http://site.ebrary.com/lib/alltitles/docDetail.action?docID=10314193

Falk, A., Fehr, E., \& Fischbacher, U. (2005). Driving forces behind informal sanctions. Econometrica, 73(6), 2017-2030. https://doi.org/10.1111/j.1468-0262.2005.00644.x

Fincham, F. D., \& Shultz, T. R. (1981). Intervening causation and the mitigation of responsibility for harm. British Journal of Social Psychology, 20(2), 113-120. https://doi.org/10.1111/j.2044-8309.1981.tb00483.x

Fukuyama, F. (2011). The origins of the rule of law (ch. 17). In The origins of political order (pp. 245-261). New York: Farrar, Straus and Giroux. 
Gauthier, I., Tarr, M., \& Bub, D. (2010). Perceptual expertise: bridging brain and behavior. Oxford University Press, USA.

Goldberg, J. H., Lerner, J. S., \& Tetlock, P. E. (1999). Rage and reason: The psychology of the intuitive prosecutor. European Journal of Social Psychology, 29(5-6), 781-795. Retrieved from http://dx.doi.org/10.1002/(SICI)1099-0992(199908/09)29:5/6<781::AIDEJSP960>3.0.CO;2-3

Greene, J. D., Sommerville, R. B., Nystrom, L. E., Darley, J. M., \& Cohen, J. D. (2001). An fMRI investigation of emotional engagement in moral judgment. Science, 293(5537), 2105-2108. https://doi.org/10.1126/science.1062872

Guglielmo, S., \& Malle, B. F. (2017). Information-acquisition processes in moral judgments of blame. Personality and Social Psychology Bulletin, online first. https://doi.org/10.1177/0146167217702375

Hareli, S., Moran-Amir, O., David, S., \& Hess, U. (2013). Emotions as signals of normative conduct. Cognition and Emotion, 27(8), 1395-1404. https://doi.org/10.1080/02699931.2013.791615

Harper, R. F. (1999). The Code of Hammurabi, King of Babylon: About 2250 B.C. The Lawbook Exchange, Ltd.

Hofmann, W., Brandt, M. J., Wisneski, D. C., Rockenbach, B., \& Skitka, L. J. (2018). Moral punishment in everyday life. Personality and Social Psychology Bulletin, 0146167218775075. https://doi.org/10.1177/0146167218775075

Hofmann, W., Wisneski, D. C., Brandt, M. J., \& Skitka, L. J. (2014). Morality in everyday life. Science, 345(6202), 1340-1343. https://doi.org/10.1126/science.1251560 
Horwitz, A. V. (1990). The logic of social control. Retrieved from //www.springer.com/us/book/9780306434754

Knobe, J. (2003). Intentional action in folk psychology: An experimental investigation. Philosophical Psychology, 16(2), 309-324. https://doi.org/10.1080/09515080307771

Kuznetsova, A., Brockhoff, P. B., \& Christensen, R. H. B. (2017). lmerTest Package: Tests in Linear Mixed Effects Models. Journal of Statistical Software, 82(13), 1-26. https://doi.org/10.18637/jss.v082.i13

Lieberman, D., \& Linke, L. (2007). The effect of social category on third party punishment. Evolutionary Psychology, 5(2), 147470490700500200. https://doi.org/10.1177/147470490700500203

Malle, B. F., Guglielmo, S., \& Monroe, A. E. (2014). A theory of blame. Psychological Inquiry, 25(2), 147-186. https://doi.org/10.1080/1047840X.2014.877340

Milgrom, P. R., North, D. C., \& Weingast, B. R. (1990). The role of institutions in the revival of trade: The law merchant, private judges, and the champagne fairs. Economics \& Politics, 2(1), 1-23. https://doi.org/10.1111/j.1468-0343.1990.tb00020.x

Moisuc, A., \& Brauer, M. (2018). Social norms are enforced by friends: The effect of relationship closeness on bystanders' tendency to confront perpetrators of uncivil, immoral, and discriminatory behaviors. British Journal of Social Psychology, 57(3), 524546. https://doi.org/10.1002/ejsp.2525

Ostrom, E. (2000). Collective action and the evolution of social norms. The Journal of Economic Perspectives, 14(3), 137-158. Retrieved from http://www.jstor.org/stable/2646923

Price, D. (1995). Energy and human evolution. Population and Environment, 16(4), 301-319. https://doi.org/10.1007/BF02208116 
Przepiorka, W., \& Berger, J. (2016). The sanctioning dilemma: A quasi-experiment on social norm enforcement in the train. European Sociological Review, 32(3), 439-451. https://doi.org/10.1093/esr/jcw014

Robinson, P. H., \& Darley, J. M. (1995). Justice, liability, and blame: Community views and the criminal law. In New Directions in Social Psychology. Boulder, CO: Westview Press.

Rothschild, Z. K., Landau, M. J., Sullivan, D., \& Keefer, L. A. (2012). A dual-motive model of scapegoating: Displacing blame to reduce guilt or increase control. Journal of Personality and Social Psychology, 102(6), 1148-1163. https://doi.org/10.1037/a0027413

Service, E. R. (1975). Origins of the state and civilization: The process of cultural evolution. New York, NY: Norton.

Shaver, K. G. (1985). The attribution of blame: Causality, responsibility, and blameworthiness. New York: Springer Verlag.

Shultz, T. R., \& Darley, J. M. (1991). An information-processing model of retributive moral judgments based on "legal reasoning." In W. M. Kurtines \& J. L. Gewirtz (Eds.), Handbook of moral behavior and development: Vol. 2: Research (pp. 247-278). Hillsdale, NJ: Lawrence Erlbaum Associates, Inc.

Sterelny, K. (2016). Cooperation, culture, and conflict. The British Journal for the Philosophy of Science, 67(1), 31-58. https://doi.org/10.1093/bjps/axu024

Stohr, K. (2011). On manners. New York, NY: Routledge.

Team, R. C. (2017). R: A language and environment for statistical computing. (Version 3.3.3). Vienna, Austria: R Foundation for Statistical Computing. 
Voiklis, J., Cusimano, C., \& Malle, B. (2014). A Social-Conceptual Map of Moral Criticism. Proceedings of the Annual Meeting of the Cognitive Science Society, Quebec City, Canada, 36 .

Wickham, H. (2016). ggplot2: Elegant graphics for data analysis. New York: Springer-Verlag. Young, L., Cushman, F., Hauser, M., \& Saxe, R. (2007). The neural basis of the interaction between theory of mind and moral judgment. Proceedings of the National Academy of Sciences, 104(20), 8235-8240. https://doi.org/10.1073/pnas.0701408104 